\title{
On Teaching Strategy of Children Dance
}

\author{
Nuowa $\mathrm{Wu}$ \\ School of Music \\ Anshan Normal University \\ Anshan, China
}

\begin{abstract}
Childhood is the best period of a person. They are curious about all new things. Children in this period are pure, naïve, lovely and clever. Therefore, it has positive and profound meaning on developing their physical and psychological health through teaching dance for them reasonably. This article mainly narrates current situation of dance education for children and existing problems, puts forward reasonable solutions, looking forward to making more and more workers of dance education realize positive effect and profound significance to correctly teach dance for children.
\end{abstract}

Keywords — children dance; current situation of teaching; ways and means

\section{INTRODUCTION}

All sectors of society pay more and more attention to education in early childhood. More and more "post-80s" parents care for future development of little "princesses" and little "princes" with concentrated attention. These parents have higher requirements for preschool education, not only exercising intelligence of children. They hope their children can "excel their masters" and develop morally, intellectually, physically and aesthetically. Therefore, a growing number of ways for early childhood education spring up like "bamboo shoots after a spring rain". But sometimes some "specialty classes" and "tutorial classes" not only make parents tricked and suffer from economic losses but also delay normal growth of children.

\section{DEVELOPMENT AND CURRENT SitUATION OF DANCE EDUCATION FOR CHILDREN IN OUR COUNTRY}

In a variety of specialties, instrumental music education suits children of about six or seven years old. The joints of children become strong in this period. Meanwhile, their intelligence is different from that of them in two to five years old. They gradually begin to correctly understand the instruction of teachers and parents. Their memory also develops to some extent. They can adapt to learning instrumental music. Language learning also suits children at this age but most suitable for children after entering school. Because both of them need certain accumulation of language and words, after entering school to learn knowledge, children can independently and fully understand it. It can arouse their learning enthusiasm and then achieve the effect of getting twofold results with half the effort. It thus appears that children

\footnotetext{
Project number: w2015007

Topic name: Research on Current Situation and Development of Dance Education for Children in Liaoning Province, general project topic of scientific research of Education Department in Liaoning province.
}

dance is more suitable for development of preschool children. Body movements of children have begun since babyhood. During the period when their language description is underdeveloped, body language and cry become the main means for infants to express emotions. When they cry, it represents they are uncomfortable and dissatisfied, such as hunger and excretion, while body language expresses delightful and excited emotions. Although most behaviors of infants in this period are unconscious movement, "gesticulating with hands and feet" is human nature. Book of Ritual and Music says, "If language cannot express the feelings, then lengthen the voice; if lengthening the voice is not enough, then use exclamatory intonation; it exclamatory intonation cannot express, then dance." Early childhood mainly refers to the period after one year old. Children enter early childhood after infancy stage. In this period, most of them begin to establish subjective consciousness, stand and walk without the help of others. After their horizon is broad, they perceive surroundings. Generally speaking, the physique, nervous system and mind of children in this period are different from the development in babyhood, especially language and body movements, which begin to have actual meaning. Meanwhile, they also have sense of independence and don't want others to help them; they begin to imitate others, with stronger sense of honor, have interest in music and fine arts and carry out selective and simple imitation learning according to their interest. In general, we can exert influence related to these contents on children after two years old, such as learning children's song and identification of color. Children in this period can learn simple, systematic and unprofessional dance, such as correct standing posture and step posture. Through scientific and systematic learning and training methods, children dance cultivates children good postures and noble temperament, lets students to establish consciousness of posture that "standing straight like a pine and sitting still like a bell", strengthens physical coordinate ability of children and control of sensitivity for rhythm, gives children the edification of beauty and develops their artistic potential. Meanwhile, it can also strengthen cultivation of children's attention, imitation, and performance, ability of visual thinking, interest, balanced capacity, coordinated ability, willpower and faith to carry out integrated development for children.

In early years of the new nation, children dance was mainly integrated in sports dancing, mainly in the form of gymnastics. The Kindergarten Provisional Regulations (Draft) issued in March 1952 stipulates six cultivation project activities in kindergarten at that time, namely physical education, understanding environment, language, drawing and manual 
training, music and calculation. Physical activities include health habit, gymnastics, game, dance and rhythmic movement, and the educational objective is to "develop basic health habit of infants, pay attention to their nutrition, exercise their physique and guarantee their physical normal development and health." It shows that the children dance at that time was carried out inside the kindergarten with the main purpose of training their physique, promoting physical and mental normal development and improvement. Meanwhile, it combines with other physical education curriculum to enrich daily teaching activities in kindergarten. However, afterwards, more and more persons with breadth of vision realize the importance of dance education for developing preschool education. For example, Mr. Huang Shimao, the famous dance educator for children in China, had made related research on systematic dance education for children since 1950s. He bases on years of dance teaching and education experience and makes professional specification for dance education from contents to forms in infant stage. The contents mainly include group dancing, rhythmic movement and performance dance. The main educational purpose is to "teach infants some shallow knowledge and skills of singing and dancing, preliminary cultivate their interest and rhythm sensation for music and dance and develop their feeling, memory, imagination and performance for music as well as cultivate their temperament and character". After the implementation of reform and opening-up policy, all sectors of society pay more and more attention to infant education. The main educational purpose of dance education for children is not only to "exercise physique" but cultivate their taste". The implementation of "one child" policy, people's pursuing for spiritual life after the improvement of their material life and the introduction of more and more foreign advanced concepts of infant education in China make people attach importance to early education for infants. At the same time, it also brings a wide range of problems. The establishment of private kindergartens realizes overall popularization of kindergarten education. But frequent occurrence of social security issues makes a great number of private kindergartens only keep them of out trouble, except for looking after "many children" and little "princess" and little "prince" "spoiled by their parents" about their diet and daily life, teaching simple knowledge stipulated by the country, in order to avoid the suspicion of "accumulating wealth by unfair means", they are unwilling to develop dance education for infants. Most competent public kindergartens shoulder the task to choose talents of dance for local youth palace and arts group of children, they take no count of universal balanced development of most children, but only choose gifted children to strengthen training for them and let them participate a variety of competition and performance, in order to "win honor" for their operation and content against other public and private kindergartens and increase source of students. In this way, in the period of infant education, they cannot make allout efforts for the development of dance education. So far, influenced by unfavorable aspects of school education, most often teachers only regard children as "containers" to accept knowledge instead of attaching importance to children's individual development. They only simply teach to let students imitate and remember and finally form unified mode. Just because teaching contents of dance in kindergartens cannot arouse learning interest of preschool children and cannot meet the requirements of parents for "high expectations for their children", more and more dance teaching in society rises. Under the influence of market economy, amateurish interestoriented classes for dancing begin to "flourish everywhere". Although the emergence of these dance classes promotes the development of dance education for infants to some extent, after all they aim at making profits. So most interest-oriented classes only emphasize body development and pay excessive attention to pursuing coordination and balance of body, which can receive effects in short time, neglect physical and mental development of infants, simplify the functions of dance education. After entering the 21st century, this situation isn't changed. In order to cater to requirements of the public and parents, most interest-oriented classes for children excessively rely on dance competition and dance graded examinations, in order to rapidly prove the so-called "teaching results" then advertise to recruit students. Some kindergartens cannot avoid this. Similar situations often appear in kindergarten education, which neglect comprehensive development of infants and cultivation of their intelligence and personality, make gifted children arrogant and willful, even use it as the standard to balance children and hurt self-esteem of parents and children who don't learn dancing. This kind of behavior has violated original intention of infant education and it is extremely inadvisable. Therefore, although the popularizing rate of dance education for children increases year after year, it is clear to see many problems are existed in it to be corrected.

\section{WAYS AND MEANS TO CORRECTLY DEVELOP DANCE EDUCATION FOR INFANTS}

Dance is an artistic form that combines timeliness and spatiality, integrates strengths of music and fine arts, realizes integrative development of people's actions and finally forms a unique artistic form. In dancing art, movement is the most important, so it is the most important technique of manifestation mode of dance. Children dance is the same, which mainly reflects life, behavior and mental activities of preschool children. Most are created according to physiologic structure and psychological characteristics of preschool children and train them dancing at proper time, which can promote development of their nervous system, respiratory system, muscle and bone, accelerate normal metabolism, make their muscle body continuous grow and develop. This shows correct dance education plays a positive and important role in healthy development of infants. Meanwhile, dance art can also cultivate children's taste. People's personality is not inherent but slowly formed through acquired cultivation and external interference. Good personality character needs comprehensive education. Dance training can strengthen development of children's emotional intelligence to feel the beauty of music and life in relaxed and pleasant atmosphere and environment. Through actions and expressions, the outside world can correctly position inner development of infants then guide them. It is easy to let children form bright and cheerful, generous and enthusiastic characters. At the same time, through coordination and unification of rhythm and body, it can strengthen development of children's nervous system to make accurate and timely judgment for the change of the outside world. The most important aspect of children dance is 
to cultivate their character and morals. Through various dance activities, children can strengthen team spirit and get along with other children, free from arrogance and impetuosity, become refined and courteous, follow the rules. It can cultivate good moral integrity of them to respect elders, love collective and our country as well as our nation.

Good education needs good guiders. Therefore, teachers play a vital role in dance education for children. Different from other professional dance for adults, the main purpose of children dance is to cultivate children's lofty sentiments, while adult dance is "technology centered" and pay attention to professional dance movement. Different educational purposes lead the different teaching methods. Dance teaching for children shall follow the nature of children's development, be scientific and reasonable, free from blindness. It mainly considers from the following aspects:

\section{A. Rationality of Dance Teaching}

All things shall consider the foundation. The key problem of dance learning of children is when the most appropriate time is for children to learn systematic dance on earth. Many dancing teachers stick to their arguments. The author thinks that according to the existing condition of material life, children above six years old can carry out related dance learning. Individual children with good development can learn dance at five years old, because systematic and professional dance training shall base on human body with basic perfect development. It is a development and improvement of athletic ability and pay attention to coordination, integrity and perfect of actions. When children's bones are not developed completely, it is impossible for them to make movements with high difficulties. If we force them, it violates general rules of physiology, which undoubtedly is a kind of damage to children's growth, even irreversible damage. Children's growth and development improves gradually with age instead of simply relying on training of dance movement. Most teachers and parents falsely assume that speeding up training for dance movement can strengthen development of children's physical ability. It causes the occurrence of phenomenon of "spoiling things by excessive enthusiasm" and causes great damage for children's physical and mental development.

For example, in terms of simple advance training, children above six years old with comparatively perfect growth and development will learn it very easily; but for children below six years old, because the development of muscle and skeleton, coordinated ability and balance isn't perfect, they will appear the situations that they stretch out the hand and foot at the same side, wag from side to side and the swing isn't unified. In order to correct these actions, teachers shall carry out single dissection exercise, repeatedly standardize actions, which make children loose happiness in learning process and greatly reduce children's interest in learning dance. Therefore, in enlightenment stage of children dance, teachers don't have to excessively pursue perfection of actions. It is totally unnecessary to act with undue haste. With age increasing, children will naturally accept and master some actions. It shows that the teaching idea of "teaching students in accordance of their aptitude" is also suitable for dance teaching. Different teaching contents and ways shall be made for children at different ages. Teachers shall not criticize children severely but check whether their teaching methods are correct.

\section{B. Instructive education and creative learning}

It is not enough for good dance education to simply rely on "teaching students in accordance of their aptitude". It is only the basis and also need multidirectional and multi-angle thinking and exploration. Firstly, consider selection of teaching contents for dance, analyze existing teaching materials of dance and select the essence and remove the dregs. Analyze rhythm, melody, action, speed, strength, emotions, key points and difficult points of excellent dance and main points of actions that can reflect this dance, after mastering it through research, then carry out second creation to create dance suitable for students, meanwhile, demonstrate correctly with proficiency, draw inferences about other cases from one instance, present briefly and succinctly, encourage children to find, think and put forward their own opinions on dance, enlighten and guide, judge correctly, arouse children's enthusiasm in learning and finally form a dance including cognition of children. Secondly, focus on passing on technical skills. The nature of children is that they are curious about all the new things, which make them innocent and lovely. Compared with other fields such as language and mathematics, the enlightening instruction of a dance teacher on students shall be more important. Therefore, dance teaching for children shall focus on imparting skills, instead of doing the actions, imitation, correction, then doing the actions again, imitating again and correcting again. The single approach will make children tired of dance learning and go against children's physical and mental development. Because the difficulty of movements for children isn't as strict as adult dance, in teaching process, teachers can explain actions first, let children master main points, key points and difficult points of actions and create dance according to their imagination. For example, for learning of leapfrog step, after the teacher explains essentials of actions, children can imagine scene by themselves, such as at dusk, a group of frogs follow their mother to go home. The teacher can choose related children's songs and let children create small dance according to basic actions. This method can arouse children's learning initiative, deepen understanding for basic actions and make classroom teaching achieve the effect of drawing inferences about other cases from one instance. Finally, because dance teaching is human centered activity and children are the main part of class, for children with simple ideas, teachers shall encourage instead of criticizing them. Only teachers' emotions reach the "cheerful" state can they appeal to children, who will pleasantly and energetically finish learning contents of dance and enjoy pleasure brought by dance.

\section{CONCLUSION}

Childhood is the best and the most precious period. The characters of children at this period are shapeable. Therefore, reasonable dance education for children can develop nature of children and correctly guide them to form good character. It also requires workers of dance education to improve ourselves and make the best use of the circumstances, completely eradicate bad behavior of "spoiling things by excessive 
enthusiasm", resist the guiding thought of "pursuing fame and wealth", actively teach dancing skills and care for growth of children. Only through inheriting correct teaching idea and using correct methods can teachers achieve the anticipated purpose and realize physical and mental development of children. It is also the final educational purpose expected by myriads of grassroots performers of early childhood education.

\section{REFERENCES}

[1] Yuan Ailing. Contemporary Preschool Curriculum Development [M], Guangzhou: Guangdong Higher Education Press, 2007.

[2] Huang Shimao. Instruction on Dance Teaching for Children [M], Shanghai: Shanghai Music Publishing House, 1990.

[3] Li Youyuan. Several Suggestions on Dance Teaching for Children [J], Dance, the 303rd issue, 2006.

[4] Lui Yisheng. Dance Education [M], Shanghai: Shanghai Music Publishing House, 2006.

[5] Cai Juemin, Yang Limei. Dalcroze Music Education Theory and Practice [M], Shanghai: Shanghai Educational Publishing House, 2005.

[6] Wen Rou. Dance Physiology [M], Shanghai: Shanghai Music Publishing House, 2004.

[7] Ping Xin. Dance Psychology [M], Beijing: Higher Education Press, 2004. 